\title{
Mapeamento da atuação do terapeuta ocupacional nos Centros de Atenção Psicossocial Álcool e Drogas (CAPS ad) do interior do estado de Sáo Paulo ${ }^{1}$
}

\author{
Carla Regina Silva ${ }^{\mathrm{a}}$, Caroline Nascimento Santos ${ }^{\mathrm{b}}$, \\ Juliana Nascimento Nogueira ${ }^{\mathrm{b}}$, Ana Paula Serrata Malfitano ${ }^{\mathrm{a}, \mathrm{c}}$ \\ aDepartamento de Terapia Ocupacional, Universidade Federal de São Carlos - UFSCar, São Carlos, SP, Brasil. \\ bUniversidade Federal de São Carlos - UFSCar, São Carlos, SP, Brasil. \\ 'Programa de Pós-Graduação em Terapia Ocupacional, Universidade Federal de São Carlos - UFSCar, \\ São Carlos, SP, Brasil.
}

\begin{abstract}
Resumo: O uso de drogas e o desafio de encontrar respostas no âmbito da assistência para o chamado uso prejudicial é uma temática atual que interpela os profissionais, serviços e gestores. O presente trabalho objetivou mapear características, profissionais e atividades realizadas pelos terapeutas ocupacionais dos Centros de Atenção Psicossocial Álcool e Drogas (CAPS ad), do interior do estado de São Paulo, por meio da aplicação de um questionário autorrespondível. Durante a coleta de dados, foram encontrados 45 CAPS ad no interior paulista, sendo que 19 profissionais colaboraram com a pesquisa; desses, 15 eram terapeutas ocupacionais. Como resultado, encontrou-se que os CAPS ad apresentam propostas regulamentadas segundo as diretrizes do Ministério da Saúde, porém a complexidade da demanda e suas múltiplas facetas com a dimensão social requerem maior discussão acerca do tipo de intervenção que tem sido empregada, assim como sobre sua eficácia. Quanto ao perfil das terapeutas ocupacionais, em sua maioria elas possuem pelo menos cinco anos de formação, pós-graduação e não optaram pela área de saúde mental e drogas. As terapeutas ocupacionais têm uma visão diferenciada de suas ações, utilizam recursos e estratégias diversas, sobretudo em atendimentos grupais e por meio de oficinas, assim como significam suas ações de formas distintas, promovendo novos projetos de vida, filiando-se a proposições de tratamento desde a abstinência até a redução de danos. Conclui-se que a assistência aos usuários dos CAPS ad é de extrema complexidade por envolver temática de caráter social com determinantes macrossociais e que necessitam de maior integração entre setores, áreas e recursos.
\end{abstract}

Palavras-chave: Drogas, Serviços de Saúde Mental, Terapia Ocupacional, Prática Institucional.

\section{Mapping of occupational therapy practice in the psychosocial Care Centers of Alcohol and Drugs In Sao Paulo state}

\begin{abstract}
Drug use and the challenge of finding answers in assistance to the so called drug abuse is a current theme that challenges professionals, services and managers. This study aimed to map features, professionals and the activities carried out by occupational therapists of the Psychosocial Care Centers of Alcohol and other Drugs (Centros de Atenção Psicossocial Álcool e Drogas - CAPS ad) in the state of Sao Paulo, through the application of a self-answerable questionnaire. During data collection, 45 CAPS ad were found in the interior of the state. Nineteen professionals cooperated with the research; 15 of them were occupational therapists. The results showed that these care centers present proposals regulated according to the guidelines of the Ministry of Health, but the complexity of
\end{abstract}

Autor para correspondência: Carla Regina Silva, Laboratório METUIA, Departamento de Terapia Ocupacional, Universidade Federal de São Carlos, Rodovia Washington Luís, Km 235, SP-310, CEP 13565-905, São Carlos, SP, Brasil, e-mail: carlars@ufscar.br

Recebido em Fev. 6, 2014; $1^{a}$ Revisão em Maio 22, 2014; 2ª Revisão em Set. 2, 2014; Aceito em Out. 30, 2014. 
the demand and its multiple facets with the social dimension require further discussion on the type of intervention that has been employed, as well as on its efficacy. Regarding the profile of the occupational therapists, most of them have at least five years of training, graduate degrees, and did not choose the area of mental health and drugs. The occupational therapists have different views of their actions, use different resources and strategies, especially in group activities and through workshops, and signify their actions in different ways, promoting new projects of life by joining treatment proposals from abstinence to harm reduction. We conclude that the assistance to the users of CAPS ad is extremely complex, because it involves social character themes with macro social determinants which require greater integration between sectors, areas and resources.

Keywords: Drugs, Mental Health Services, Occupational Therapy, Institutional Practice.

Parece improvável que a humanidade, de um modo geral, algum dia seja capaz de passar sem paraisos artificiais. A maioria dos homens e mulheres leva uma vida tão sofredora em seus pontos baixos e tão monótona em suas eminências, tão pobre e limitada, que os desejos de fuga, os anseios para superar-se, ainda por uns breves momentos, estão e tem estado sempre entre os principais apetites da alma (HUXLEY, 2002, p. 27).

\section{Introdução}

\subsection{Políticas públicas de saúde no Brasil e a questão das drogas}

A visão sobre a droga ser uma "ameaça à sociedade" é uma construção social contemporânea. Historicamente, o uso de substâncias esteve associado aos rituais, aos costumes e aos próprios valores coletivos de diferentes comunidades (BERRIDGE, 1994). Apesar das diferenças culturais em relação à utilização e às finalidades do uso das substâncias psicoativas, elas são consideradas como possuidoras de uma função presente em todos os lugares: a possibilidade de alteração da percepção, do humor e das sensaçóes, sendo que sua aceitação depende das características da comunidade em questão, tais como valores e cultura, e não do risco propriamente dito que a droga representa.

No entanto, como propóem Delgado (2005) e Brasil (2007), o Estado não assumiu sua responsabilidade para com o desenvolvimento de políticas públicas direcionadas a questão do consumo de drogas. Havia, até recentemente, uma lacuna de iniciativas consistentes e regulares. Ainda, explicam os autores, que em função dessa ausência de políticas públicas de saúde consistentes, instituiçóes da justiça, da segurança pública, da educação e associaçóes filantrópicas e religiosas tomaram frente da situação. Como resultado, foram criadas e disseminadas práticas e modelos de cuidado disciplinares ou de cunho religiosos baseados, predominantemente, na internação e segregação e tendo como principal meta a abstinência.

Segundo o Relatório Mundial sobre Drogas 2014 (UNITED..., 2014) houve um aumento não linear na produção e uso de drogas ilegais ao redor do mundo. A produção e o uso de substâncias que estão sob controle internacional permanecem em grande parte estáveis, calcula-se que em 2012 entre 162 e 324 milhóes de pessoas (3,5\% a 7,0\% da população entre 15 e 64 anos) consumiram pelo menos uma vez alguma droga ilícita, ainda que as tendências de oferta e demandas de drogas tenham sido desiguais entre regióes e países e entre tipos de drogas. Enquanto que a taxa de consumidores habituais e pessoas que sofrem transtornos advindos do consumo ou dependência se manteve estável, entre 16 e 39 milhóes de pessoas.

A Secretaria Nacional de Políticas sobre Drogas do Ministério da Justiça do Brasil aponta que cerca de 5\% da população brasileira entre 15 e 64 anos usou drogas ilícitas pelo menos uma vez no último ano, dentre elas a mais consumida no mundo é a maconha ${ }^{2}$ (BRASIL, 2011a).

Vale destacar, contudo, que é o álcool, uma droga legal, a mais consumida no mundo e considerada um dos maiores problemas da saúde pública no Brasil (BRASIL, 2004a).

Por esse motivo, ressalta-se a necessidade de problematizar a distância existente entre as chamadas políticas de combate ${ }^{3}$ ao uso de drogas lícitas e ilícitas, visto que são regulamentadas a partir de setores distintos ligados à saúde e à justiça. Ainda que o enquadramento jurídico e social seja diferente, no interior da legalidade e ilegalidade social, a forma de se ver aqueles envolvidos com um ou outro tipo de droga é bastante expressiva, ultrapassando os reconhecidos efeitos de cada substância, bem como suas consequências sociais. Os fornecedores de substâncias psicoativas lícitas são respeitados, pois participam do mercado formal e, portanto, da economia do país, vistos normalmente como parceiros dos formuladores 
de determinadas políticas. Já os fornecedores de substâncias psicoativas ilícitas estấo do lado oposto, geralmente vistos como criminosos e, definitivamente, inimigos dos formuladores de políticas (BRASIL, 2004b), embora sejam também membros da economia nacional, porém do lado das açôes ilegais.

Reconhecendo a diferença de estatuto social que o comércio legal e ilegal ocupam, cabe o questionamento acerca das instâncias conceituais, jurídicas, sociais e morais que necessariamente articulam-se em torno do comércio para, assim, ser possível problematizar quais são as reais necessidades dos sujeitos e da sociedade e as formas mais eficazes de atuação sobre elas.

Quando se debruça sobre as diferenças entre a legalidade e a ilegalidade é preciso lembrar que "[...] tal diferença perde o sentido se formos comparar os danos causados pelas diferentes substâncias. De acordo com relatórios da OMS, os danos causados pelo álcool superam, em muito, os danos causados por substâncias ilícitas" (BRASIL, 2004b, p. 118).

Nesse debate, quando se adentra a questão do tratamento e o que é ou não um uso abusivo, não há um consenso sobre quais os melhores procedimentos a serem aplicados. No Brasil é candente a discussão sobre os interesses financeiros em torno da atenção em saúde para aqueles considerados dependentes de drogas e as diferentes modalidades de cuidado para tal (CONSELHO..., 2013). No âmbito da saúde mental, campo em que se insere essa discussão, a Reforma Psiquiátrica trouxe um novo paradigma de atenção e cuidado que se coaduna com uma proposição de serviços de base comunitária, extra-hospitalares e chamados de "porta aberta", de acordo com as proposiçóes dos Centros de Atenção Psicossocial (BRASIL, 2004b). Contudo, é importante assinalar o atual debate na sociedade brasileira e as respostas governamentais sobre a necessidade de internação como primeira escolha de tratamento e a aplicaçáo de propostas que náo vão ao encontro das diretrizes defendidas pelo movimento da reforma psiquiátrica, as quais são amparadas por diversas portarias ministeriais e, mais especificamente, pela Lei 10.216 (BRASIL, 2001), que modificou toda a concepçáo em torno da assistência à saúde mental no Brasil.

Em termos jurídicos, a Lei n. 11.343/06 (BRASIL, 2006), conhecida como Lei de Drogas, articula-se à Política de Saúde Mental do Ministério da Saúde, por meio da Lei 10.216. Tal documento descreve as orientaçóes gerais e as diretrizes para a abordagem da questáo drogas, sendo elas: 1) prevenção, 2) tratamento, recuperação e reinserção social, 3) redução dos danos sociais e à saúde, 4) redução da oferta, e 5) estudos, pesquisas e avaliaçóes (BRASIL, 2011a).

Enquanto perspectiva teórico-prática, essa política se baseia nos princípios da Redução de Danos ${ }^{4}$, tendo em vista o rompimento com as metas de abstinência como única possibilidade terapêutica (BRASIL, 2011a).

Entretanto, tais diretrizes contradizem a atual proposta de combate ao crack, segundo sua própria denominação, materializada pelo Programa "Crack, é possível vencer" pelo governo federal. No estado de Sáo Paulo, o "Programa Recomeço", de iniciativa integrada entre os poderes Judiciário e o Executivo, por meio de ações coordenadas entra as Secretarias Estaduais da Saúde, da Justiça e Defesa da Cidadania e do Desenvolvimento Social, tem a internação compulsória como forma de tratamento e diretriz (SÃO PAULO, 2014). Ambos programas trazem dados alarmantes que acabaram por colocar o crack em uma situação de urgência, o que náo se confirma como necessidade entre os padróes de uso no país. Porém, o mais grave relaciona-se à legitimação do uso da internação, da internação compulsória e de outras formas de isolamento social como meio de atenção (CONSELHO..., 2013), distanciando-se dos referenciais da Reduçáo de Danos, em curso na Política de Saúde Mental brasileira.

O Relatório Final da IV Conferência Nacional de Saúde Mental Intersetorial, realizada em 2010, enfatiza, em seu artigo 485, que o enfrentamento da problemática do uso e abuso de álcool e outras drogas requer a implantação e o desenvolvimento, nos três níveis de atenção, de políticas públicas intersetoriais, em consonância com as diretrizes da Reforma Psiquiátrica, do Sistema Único de Saúde (SUS), do Sistema Único de Assistência Social (SUAS), do Programa Nacional de Direitos Humanos (PNDH) e do Programa de Atençáo Integral a Usuários de Álcool e Outras Drogas (BRASIL, 2010, p. 85). Também, no artigo 490, em relação à rede, as propostas apontam, entre outras questóes, para a necessidade de se garantir sustentabilidade das açóes de redução de danos no território, fortalecendo a gestão intra e intersetorial. "Os Centros de Atenção Psicossocial Álcool e Drogas - CAPS ad devem operar com a lógica de redução de danos e promover a inserção social de seus usuários" (BRASIL, 2010, p. 86). 


\section{Os Centros de Atenção Psicossocial Álcool e Drogas (CAPS ad)}

Os Centros de Atenção Psicossocial (CAPS), no seu surgimento, foram implementados para substituírem o então modelo hospitalocêntrico vigente para a diminuição de internaçóes em hospitais psiquiátricos, visando à mudança do modelo assistencial. Foram criados oficialmente a partir da Portaria GM n. 224/92 e são atualmente regulamentados pela Portaria n. 336/GM, de 19 de fevereiro de 2002, integrando a rede do Sistema Único de Saúde (SUS) (BRASIL, 2004c).

Os CAPS devem assumir o papel de articuladores e compor de forma central as redes de saúde, tanto cumprindo suas funçóes na assistência direta e na regulamentação da rede de serviços de saúde quanto na promoção da vida comunitária e da autonomia dos usuários, articulando os recursos existentes em outras redes: sociossanitárias, jurídicas, cooperativas de trabalho, escolas, empresas etc. Eles necessitam permanentemente de outras redes sociais e de outros setores afins como forma de suporte e efetividade de trabalho para a inclusão social das pessoas (BRASIL, 2004c, 2011b).

Os CAPS devem contar com um espaço adequadamente estruturado com recursos físicos para que possa desenvolver suas funçóes plenamente, tais como: consultórios para atividades individuais (consultas, entrevistas, terapias); salas para atividades grupais; espaço de convivência; oficinas; refeitório (os CAPS devem ter capacidade para oferecer refeiçóes de acordo com o tempo de permanência das pessoas na unidade); sanitários; área externa para oficinas, recreação e esportes. Os CAPS podem oferecer três modalidades diferentes de atendimento, sendo elas o atendimento intensivo, o semi-intensivo e o não intensivo, com intervençôes: atendimento individual, em grupo e para a família, atividades comunitárias e assembleias ou reuniôes de organização do serviço (BRASIL, 2004c, 2011b).

As oficinas terapêuticas desenvolvidas nos CAPS são uma das principais formas de tratamento do serviço. São atividades realizadas em grupo com a presença e orientação de um ou mais profissionais, monitores ou estagiários. Variam de acordo com os interesses e as necessidades dos usuários, com a possibilidade dos técnicos do serviço e têm sempre em vista a maior integraçáo social e familiar possíveis, a realização de atividades produtivas, o exercício da cidadania, bem como a manifestaçáo de sentimentos e problemas e o desenvolvimento de habilidades corporais (BRASIL, 2004c).

Mais recentemente, a Portaria n. 3.088/2011 (BRASIL, 2011b) especifica os CAPS, incluindo aqueles destinados para atenção aos usuários de álcool e outras drogas, como locais estratégicos para a efetivação da Rede de Atenção Psicossocial (RAPS), a qual deve integrar a rede naquilo que concerne à atenção às pessoas com sofrimento ou transtorno mental e com necessidades decorrentes do uso de crack, álcool e outras drogas no âmbito do Sistema Único de Saúde. Define:

CAPS ad: atende adultos ou crianças e adolescentes, considerando as normativas do Estatuto da Criança e do Adolescente, com necessidades decorrentes do uso de crack, álcool e outras drogas. Serviço de saúde mental aberto e de caráter comunitário, indicado para municípios ou regiôes com população acima de setenta mil habitantes; CAPS AD III: atende adultos ou crianças e adolescentes, considerando as normativas do Estatuto da Criança e do Adolescente, com necessidades de cuidados clínicos contínuos. Serviço com no máximo doze leitos para observaçáo e monitoramento, de funcionamento 24 horas, incluindo feriados e finais de semana; indicado para municípios ou regióes com população acima de duzentos mil habitantes (BRASIL, 2011b, p.60).

Os CAPS ad são voltados para o atendimento diário para usuários de álcool e outras drogas, podem ter leitos de repouso, com a finalidade exclusiva de tratamento de desintoxicação e devem estar baseados na Redução de Danos como estratégia de intervenção (BRASIL, 2004c). São previstos para municípios com mais de 70 mil habitantes, devem ser porta aberta e, prioritariamente, desenvolver açôes comunitárias (BRASIL, 2011b).

Utilizadas internacionalmente e apoiadas pelas instituiçóes responsáveis pela formulação da Política Nacional sobre Drogas, as estratégias de Redução de Danos constituem um conjunto de princípios e açóes para a abordagem dos problemas relacionados ao uso de drogas. Essas, por sua vez, não partem do princípio de que deve haver imediata e obrigatória extinção do uso de drogas (seja no âmbito da sociedade, seja individualmente) e sim formulam práticas que diminuem os danos para aqueles que delas se utilizam e para os grupos sociais com que as pessoas convivem (BRASIL, 2011a).

A perspectiva da reduçấo de danos é crítica ao proibicionismo, mas pode conviver com 
ele, pode-se dizer que tal visão alternativa não implica numa percepção positiva, ou mesmo isenta de juízos de valor, do uso de drogas psicoativas. O consumo destas substâncias é percebido como "inevitável”, o que não significa "desejável”. Além do esforço para se distinguir dos defensores de transformaçóes mais radicais da situação legal dos psicoativos, a perspectiva das políticas de redução de danos se dá a partir de um ponto de vista negativo: a preocupação está em minimizar prejuízos dada a impossibilidade de um mundo abstêmio (RODRIGUES, 2003, p. 268).

A equipe mínima de um CAPS ad deve ser constituída por: um médico psiquiatra, um enfermeiro com formação em Saúde Mental, médico clínico (responsável pela triagem, avaliação e acompanhamento das intercorrências clínicas), quatro profissionais de nível superior entre as seguintes categorias profissionais: psicólogo, assistente social, enfermeiro, terapeuta ocupacional, pedagogo ou outro profissional necessário ao projeto terapêutico e, por fim, seis profissionais de nível médio: técnico e/ou auxiliar de enfermagem, técnico administrativo, técnico educacional e artesão.

\section{Atuação da terapia ocupacional}

A demanda pelo trabalho multidisciplinar ou transdisciplinar da equipe dos CAPS ad deve ocorrer de forma muito bem estruturada e articulada com os diversos setores existentes que envolvem essa problemática. Dentre os profissionais capacitados para compor as equipes estão os terapeutas ocupacionais, que podem contibuir para com os pressupostos e enfrentamentos das políticas nacionais apresentadas, uma vez que tradicionalmente têm uma formação interdisciplinar e atuam tanto na área da saúde, da educaçáo, como também no campo social.

A Terapia Ocupacional volta-se às possibilidades reais e efetivas de participação na vida social com autonomia, partindo da questão do acesso aos direitos e bens sociais. A partir dessa perspectiva, as atividades passaram a ser elementos importantes no movimento de desconstrução de uma lógica excludente e alienante (CASTRO et al., 2001), podendo o profissional ser responsável pela criaçáo de novas possibilidades e novas configuraçôes de práticas de intervenção direcionadas à vida cotidiana.

O sentido fundamental das atividades é ampliar o viver e torná-lo mais intenso, nunca diminuí-lo ou esvaziá-lo. Elas nos enriquecem, nos permitem reestruturar a experiência em níveis de consciência sempre mais integrados, tornando nossa compreensão mais abrangente, intensificando, assim, o sentimento da vida. Elas abrem um campo de aquisiçôes, habilitações e prevenções e podem operar como fatores de fortalecimento nos processos de potencialização da inclusão sociocultural. Cada atividade realizada dá origem a novas proposiçóes, e nesse sentido é preciso entendê-las como altamente integradoras de outros campos das atividades das pessoas (CASTRO et al., 2001, p. 55).

Para Tedesco (1997), numa discussão mais individualizada da atenção a pessoa que faz uso de drogas, os terapeutas ocupacionais podem proporcionar um espaço de suporte organizador e reorientador para os sujeitos quando esses iniciam o tratamento, contribuindo tanto para o aumento da adesão quanto para uma rápida reconstrução da realidade dessas pessoas, viabilizando outras intervençôes terapêuticas, sendo as atividades elementos facilitadores da intervenção.

Oliveira (2006) ressalta que, entre os principais objetivos terapêuticos ocupacionais no trabalho com pessoas que usam drogas, estão: - Possibilitar expressão simbólica e subjetiva; - Promover compreensão a respeito da problemática relacionada ao abuso de substância química, por meio de uma aprendizagem centrada na realidade da pessoa; - Estimular potencialidades favorecendo o fenômeno da construção pessoal, utilizando-se de diferentes linguagens: plástica, corporal, literária etc.; - Incentivar melhoria da qualidade de vida, atentando para reformulação de hábitos e estilos de vida; - Favorecer reinserção social e reconstrução da cidadania, considerando de fundamental importância a capacitaçáo e/ou retorno profissiomal, a exemplo das cooperativas de trabalho ou oficinas de produção e geração de renda; - Melhorar as relações (família, trabalho, sociedade); - Atuar em um contexto transdisciplinar.

Karaguilla (2010) defende que a Terapia Ocupacional compreende o ser humano como um ser capaz de "fazer", com foco na sua experiência. Durante o processo terapêutico ocupacional são possibilitadas formas inéditas e criativas de fazeres, objetivando propiciar vivências de impulsos criativos, portanto, instrínsecos à relação estabelecida no processo.

Este emergir de experiências criativas mais especificamente na clínica de terapia ocupacional facilita a construção de uma relação com o mundo sem a intermediação da substância psicoativa, modificando então a relação do sujeito com o obejto de dependência (KARAGUILLA, 2010, p. 130).

Pereira e Malfitano (2012) destacam que a compreensão do universo das drogas, especificamente 
abordando os jovens, só ocorrerá a partir da utilização de abordagens que valorizem a história de vida e o local social do sujeito, notadamente sua classe social. Afirmam que há uma insuficiência nos dados clínicos, estatísticos e epidemiológicos, carecendo de metodologias participativas para a compreensão, apreensão e intervenção sobre o fenômeno.

Importante apontar que a intervenção terapêutica ocupacional deve voltar-se náo apenas para o aspecto individual da atenção mas, sobremaneira, aos pontos coletivos e territoriais que o trabalho no CAPS requer, conforme apontado em seus princípios.

\section{Objetivos}

O objetivo geral dessa pesquisa foi mapear e descrever as características dos Centros de Atenção Psicossocial Álcool e Drogas (CAPS ad) do interior do estado de São Paulo.

Entre os seus objetivos específicos encontram-se a descrição do perfil da instituição, equipe e usuários; a identificaçấo da presença dos terapeutas ocupacionais; bem como o levantamento sobre as atividades, técnicas, procedimentos e dinâmicas utilizados pelos profissionais de terapia ocupacional em CAPS ad.

\section{Procedimentos metodológicos}

O procedimento metodológico voltou-se para o desenvolvimento de um questionário, que resultou em 37 questôes, que abordaram informaçóes acerca de: dados pessoais, formação profissional, caracterização da instituição ou do serviço e de sua equipe, atuação do terapeuta ocupacional e perfil dos usuários do serviço.

Primeiramente foi realizado o levantamento dos CAPS ad do estado de São Paulo, tendo como base os dados do Ministério da Saúde do ano de 2012 (BRASIL, 2012). Segundo essa fonte, havia 69 CAPS ad no estado, sendo 24 somente no município de São Paulo, correspondendo a quase $35 \%$ do total de serviços. Gerou-se uma listagem com informaçóes dos 69 CAPS ad e foi realizado contato telefônico com todos eles.

Foram confirmados 65 CAPS ad em funcionamento regular em todo o estado. Ainda nesse mesmo contato foi verificada se havia ou náo a presença de terapeutas ocupacionais nas equipes daqueles serviços. Foi verificada a presença de 84 terapeutas ocupacionais contratados e atuando, sendo 38 somente na cidade de Sáo Paulo, correspondendo a pouco mais de $45 \%$ do total de profissionais no estado paulista em atuação nessa modalidade de serviço.
Nesse momento optou-se por realizar um recorte geográfico para os serviços concernentes ao interior do estado de Sáo Paulo, pois a cidade de São Paulo apresenta algumas normatizaçóes próprias que criam situações particulares, além das especificidades territoriais de uma metrópole de seu porte. Assim, encaminhamos os questionários elaborados apenas aos serviços do interior paulista.

Para realizar o envio dos questionários foi feito um segundo contato telefônico para que se pudesse enviar o convite de colaboraçáo com a pesquisa, direcionado aos terapeutas ocupacionais. Como em alguns CAPS ad não havia terapeutas ocupacionais na equipe, foi feito, então, o convite aos coordenadores, para que respondessem ao questionário, excluindo as perguntas específicas sobre a atuação do terapeuta ocupacional.

Ao todo, 54 pessoas foram contatadas, sendo 46 terapeutas ocupacionais atuantes no interior paulista e oito coordenadores de outras categorias profissionais. Desses, 41 aceitaram responder o questionário. Entretanto, apenas 19 efetivaram sua colaboraçáo, sendo 15 terapeutas ocupacionais e quatro coordenadores de serviços. Um questionário foi desprezado por não ter sido respondido de acordo com o instrumento encaminhado. Assim, a pesquisa contou com a participação de $33 \%$ das terapeutas ocupacionais representantes de todo o universo do interior paulista.

Destaca-se que todos os procedimentos éticos em pesquisa foram respeitados e todos os colaboradores assinaram o Termo de Consentimento Livre e Esclarecido. Foram solicitadas, apenas, informaçóes institucionais para composição dos dados analisados.

\section{Resultados e discussão}

\subsection{Instituição/Serviço}

Enquanto caracterização da natureza de funcionamento, $90 \%$ dos serviços que participaram da pesquisa eram serviços públicos da secretaria municipal de saúde local, sendo que somente dois estavam classificados como Organização Não Governamental (ONGs).

Os CAPS ad podem ser classificados como CAPS ad com leito 24 h (CAPS III), CAPS ad sem leito (CAPS I ou II); CAPS ad i, direcionados para o público de crianças e adolescentes, ou Ambulatório (BRASIL, 2011b). Noventa e cinco por cento dos serviços eram CAPS ad sem leito (tipo CAPS I ou II) e apenas um atuava como ambulatório, ou seja, não foi encontrado nenhum serviço que oferecesse leito na sua modalidade de tratamento. 
O tempo de funcionamento dos serviços variou de um mês a 16 anos, porém observou-se que 10 deles estavam em funcionamento entre seis e nove anos ${ }^{6}$.

À pergunta sobre a faixa etária de atendimento, encontrou-se que $83 \%$ atendiam adolescentes, ou seja, tal atendimento estava presente em 14 CAPS ad.

Quando questionado sobre os principais parceiros dos CAPS ad, as respostas foram direcionadas para os próprios serviços da saúde. Trinta por cento dos colaboradores declararam que a parceria estava no próprio setor saúde. Dentre as respostas, nas quais poderiam se assinalar múltiplos itens, encontram-se: as redes de saúde mental (para cinco respostas), hospitais municipais (duas respostas), hospitais psiquiátricos (cinco respostas), pronto-socorro (uma resposta), conselho de saúde (uma resposta), unidades básicas de saúde/UBS (cinco respostas), estratégia de saúde da família (três respostas), secretaria da saúde (uma resposta). Esses dados mostram e confirmam que a visão das drogas é tida muito mais como um problema de saúde pública do que como um problema amplo intersetorial, o qual deveria demandar muitas outras estratégias, ampliando os parceiros daqueles equipamentos.

\subsection{Perfil da equipe}

As equipes técnicas eram compostas de 11 a 16 profissionais, sendo que três CAPS ad apresentavam 12 profissionais na equipe, dois apresentam 14 e outros dois, 18. A menor equipe contava com cinco profissionais e a maior, com 23.

Entre as profissôes que estavam em exercício nos serviços, o terapeuta ocupacional estava presente em 16 CAPS ad participantes dessa pesquisa, assim como os assistentes sociais e enfermeiros, ou seja, em 95\% do universo consultado. Os psicólogos compunham $100 \%$ das equipes. Um destaque é que a presença de médicos psiquiatras encontrava-se apenas em 75\% deles e médicos clínicos, em 59\%.

Também foram encontrados profissionais de Fisioterapia, Pedagogia, Educação Física, Farmácia, Nutrição e Psicopedagogia.

Entre os demais profissionais relatados, estavam técnicos de enfermagem, pessoal de serviços gerais e aqueles com a função de promoçáo de atividades, como oficineiros, professor de artes e terapeuta corporal. Foi também relatada a presença de coordenadores, escriturários, recepcionistas, motoristas e guardas de patrimônio.

Quanto à remuneração desses profissionais, 89\% dos locais pagavam entre 3 e 5 salários-mínimos, $11 \%$ se dividiam no recebimento de 1 a 2 salários-mínimos e de
5 a 7 salários-mínimos. Um local destacou que alguns profissionais recebiam mais de 10 salários-mínimos.

A contratação da equipe profissional em $70 \%$ dos serviços ocorreu através de concursos públicos. Em 18\% eram realizados processos seletivos e em $12 \%$ eram aplicadas ambas as modalidades.

Com relação à forma de acompanhamento da realizaçáo do trabalho, em $70 \%$ deles havia a realização de supervisão institucional ou alguma modalidade de formaçáo para a equipe.

\subsection{Perfil dos usuários}

Composição do perfil majoritário dos usuários que frequentavam os CAPS ad: homens, conforme relatado em $88 \%$ dos questionários. A menor faixa etária referida foi de 15 anos e a maior, de 55, com uma média, portanto, de 35 anos.

Situações de baixa renda, baixa escolaridade, comprometimento psiquiátrico e cognitivo, vulnerabilidade social e falta de estrutura familiar foram outras informaçóes que constaram nas respostas abertas dos colaboradores sobre o perfil dos usuários.

Destaca-se que se tratam de dados de extrema relevância para compreensão do perfil de usuários em atenção nos serviços, na medida em que demonstram a associação de diferentes situaçôes ao uso de drogas, podendo contribuir de forma central para se traçarem planos de intervenção que contribuam, efetivamente, com a vida daquelas pessoas.

Em relação à droga mais utilizada, momento em que o instrumento admitia múltiplas respostas, o álcool teve sua maior apariçãa (oito respostas), seguido do uso de múltiplas substâncias (seis respostas), crack (quatro respostas), cocaína (três respostas) e maconha (três respostas).

Entre as substâncias responsáveis pela dependência, o álcool novamente apareceu como o mais citado (quatro respostas), seguido do crack e da cocaína (duas respostas cada), múltiplas substâncias/dependência cruzada (uma resposta) e maconha (uma resposta).

No item sobre como os usuários chegavam ao serviço, novamente admitindo múltiplas respostas, $100 \%$ destacaram a demanda espontânea, seguido por encaminhamentos dos serviços de saúde (14/17), através de açôes da assistência social (6/17), pelo poder judiciário (6/17) e família (5/17). Outras maneiras citadas foram contato de outros serviços, amigos, chefia do trabalho, indicaçáo de ex-pacientes, encaminhamento pelo serviço de 
medidas socioeducativas (no caso de adolescentes em conflito com a lei) e por meio de comunidades terapêuticas.

\subsection{Perfil das terapeutas ocupacionais}

\subsubsection{Graduação em terapia ocupacional}

Constatou-se que $57 \%$ das terapeutas ocupacionais (todas do gênero feminino) que trabalham nos CAPS ad do interior do estado de São Paulo se formaram em universidades públicas paulistas. As universidades públicas citadas foram: (3) Universidade Estadual Paulista Júlio de Mesquita Filho (UNESP - campus Marília), (2) Universidade de São Paulo (USP - campus Sáo Paulo), (2) Universidade Federal de São Carlos (UFSCar - campus São Carlos) e (1) Universidade Federal de São Paulo (UNIFESP - campus Baixada Santista). Já as instituiçóes privadas de ensino foram responsáveis pela formação de $43 \%$ dos terapeutas ocupacionais, tendo ocorrido em: (2) Pontifícia Universidade Católica de Campinas, (1) Centro Universitário Claretiano Batatais, (1) Centro Universitário São Camilo, (1) Universidade de Sorocaba (UNISO) e (1) Centro Universitário Católico Salesiano Auxilium de Lins.

Das 14 terapeutas ocupacionais, quatro (29\%) se formaram antes do ano de 2000 (nos anos 1979, 1990, 1991 e 1999), cinco terapeutas ocupacionais $(35,5 \%)$ graduaram-se entre os anos de 2001 e 2007 e, com o mesmo percentual, as recém-formadas, consideradas aquelas com graduaçáo a partir de 2009.

\subsubsection{Atividades de capacitação e pós-graduação}

Em relação à continuidade da formação, 93\% das terapeutas ocupacionais realizaram cursos de pós-graduação, strictu e lato sensu, cujas principais temáticas foram: Saúde Mental, Dependência Química, Reabilitação, Neuropediatria e Integração Sensorial. Uma terapeuta ocupacional (7\%) realizou Especialização/Aprimoramento e também o Mestrado tendo como temática principal a Dependência Química e a Saúde Mental. A Figura 1 apresenta a visualização gráfica dos dados.

\subsubsection{Inserção das terapeutas ocupacionais nos CAPS ad}

Cinquenta e sete por cento das terapeutas ocupacionais que atuavam nos CAPS ad do interior

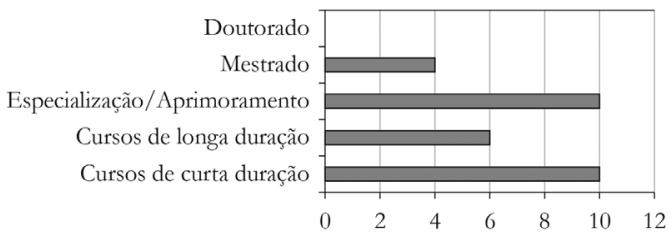

Figura 1. Atividades de capacitação das terapeutas ocupacionais.

do estado de São Paulo ingressaram no serviço por meio de concursos públicos. Dentre elas, $50 \%$ relataram não possuir afinidade com a área de Saúde Mental/Dependência Química na ocasião de assumir seu cargo.

Em relação às terapeutas ocupacionais que mencionaram ter afinidade com a área, duas (14\%) relataram que o interesse surgiu desde a graduação, justificando o motivo para terem se inserido nos CAPS ad, as demais profissionais afirmam que o interesse se deu a partir do ingresso no CAPS ad e devido a empregos anteriores na área de saúde mental (hospitais psiquiátricos).

Tais dados demonstram que a realização do concurso público náo garante a vinda de pessoas com perfil e afinidade com a área, demonstrando a necessidade de educaçáo continuada para que se invista no aprimoramento e muitas vezes na formação da equipe de trabalho.

Gallassi e Santos (2013) discutem que o desconhecimento dos profissionais em relação à temática drogas e as ações junto aos usuários em sofrimento pelo abuso de álcool e outras drogas se apresenta desde a graduação e é uma problemática a ser debatida e superada, pois se encontra nas formaçóes de todas as categorias profissionais da área da saúde.

\subsubsection{Proposta de intervenção dos CAPS ad}

Dentre as terapeutas ocupacionais, $21 \%$ delas relataram que fundamentavam suas ações na Redução de Danos para o desenvolvimento de seu trabalho com o público-alvo em questão.

No cômputo das instituiçôes em geral, 29\% dos CAPS ad referiram que lançavam mão da Redução de Danos concomitantemente à outra técnica (Cognitivo-Comportamental, Psicodinâmica, Prevenção à Recaída, Teoria da Complexidade, Psicologia Social, Abstinência). Contudo, temos que 36\% não referiram a Reduçáo de Danos como estratégia de trabalho, ou seja, essa diretriz não foi 
citada como foco do tratamento. A Prevenção à Recaída como ação única de trabalho foi citada por representantes de $14 \%$ dos CAPS ad. A Reabilitação Psicossocial foi mencionada apenas por uma pessoa (7\%), e outros 7\% (uma resposta) referenciaram a combinação da Reabilitação Psicossocial com a Promoção da Saúde e Prevenção ao Uso Indevido de Drogas.

Tem-se, aqui, um dado de extrema relevância quando se busca o diálogo com a política nacional de saúde mental e as açóes em desenvolvimento pelo local escolhido como dispositivo central da formação da rede de atençáo psicossocial: os CAPS. Observa-se um índice baixo de referência à Redução de Danos e à Reabilitação Psicossocial, pressupostos da política nacional e, teoricamente, princípios diretivos dos serviços.

Das terapeutas ocupacionais que responderam ao questionário, $21 \%$ exerciam funções de gestão do serviço.

Em $28,5 \%$ dos serviços, a função da terapeuta ocupacional era realizar o Atendimento/Acompanhamento Individual, Grupal e Familiar. Em 21\%, ademais dessas funções, a terapeuta ocupacional realizava atendimentos, acompanhamentos no nível territorial, ou seja, para além do espaço institucional.

\subsubsection{Atividades e recursos utilizados}

Quando solicitado às terapeutas ocupacionais alguns exemplos de atividades ou recursos que elas utilizavam no cotidiano de sua prática profissional, obtivemos um número significativo de exemplo de açôes, sendo que as respostas foram agrupadas a seguir em cinco categorias.

Os grupos (grupos e oficinas) foram as estratégias mais citadas pelas profissionais, aparecendo em 93\% das respostas. Os exemplos sugeridos pelas profissionais foram: grupos e/ou oficinas de acolhimento, entrada, grupos próprios de terapia ocupacional, cidadania, atualidade e memória. Outra categoria presente nas respostas estava relacionada aos procedimentos próprios do serviço, tais como, triagem, acolhimento, escuta e busca ativa, abordagem de entrevista motivacional, abordagem de rua, análise e orientação das ocupaçóes e dos fazeres dos usuários, manutenção da abstinência, assembleias e acompanhamento dos usuários por meio de profissional de referência. Atividades realizadas em ambiente externo ao CAPS também foram destacadas: passeios pelos espaços públicos, atividades em Centro de Convivência e cinema.
Atividades corporais e expressivas foram citadas: consciência corporal, alongamento, relaxamento, dança de saláo e teatro. Outros exemplos relacionados a determinadas técnicas/materiais/atividades foram: artes e artesanato (quatro respostas), atividades com fios (quatro respostas), pintura (três respostas), jogos, culinária, marcenaria, jardinagem e horta (citados duas vezes cada) e, ainda, mosaico, bordado, costura, atividades recreativas e culturais.

\subsubsection{Concepção das terapeutas ocupacionais acerca da "Atividade"7}

Quando questionadas sobre o conceito de atividade, as terapeutas ocupacionais apresentaram suas reflexóes acerca desse termo, ressalta-se que muitos são os termos utilizados para definir essa estratégia-ação na Terapia Ocupacional (GALHEIGO, 1988; LIMA; OKUMA; PASTORE, 2013). A polissemia dos termos traz possíveis interpretaçôes, assim como revela as inúmeras fronteiras epistemológicas entre si. Como afirma Medeiros (2010), as divergências classificatórias na Terapia Ocupacional ocorrem devido às distintas perspectivas dos métodos de análise, referentes às mudanças de paradigmas de cada concepção histórico-epistemológica.

Para metade das terapeutas ocupacionais, a atividade também é concebida de forma mais ampla como ação, fazer e práxis humana, baseada em concepções que empreendem sentidos plurais para sua utilização, como pode ser observado nos excertos a seguir:

Minha concepção de atividade aproxima-se do conceito de práxis, ou seja, do entendimento de que é parte da essência humana ser ativo, criativo e prático, o que faz do homem um ser capaz de transformar o mundo e a si mesmo (S2). $A$ atividade, o fazer humano, é o que dá sentido à vida, é por ele que podemos modificar a nós mesmos, a sociedade. É pelo fazer humano que construimos nossa história e fazemos parte da história do outro (S4). Todo e qualquer fazer do individuo, que pode mudar de acordo com variáveis como idade, sexo, contexto, lugar etc. (S6). É uma ação humana. Tudo o que fazemos de uma forma mais estruturada na vida é uma atividade. Desta forma, está totalmente relacionada à funcionalidade do sujeito (S12). Atividade éa capacidade de expressão humana, de forma ampla, individual ou comunitária (S13). Atividade é qualquer ação realizada pelo ser 
humano, sendo esta lhe proporcionando prazer ou não (S14).

Parte das respostas apresentou o conceito de atividade como instrumento/meio/fim das açóes do terapeuta ocupacional:

$A$ atividade tem que ser um meio pelo qual eu consiga entender e perceber os aspectos do paciente e um facilitador para que a intervenção aconteça de forma contextualizada e que faça sentido para o paciente (S2, grifo nosso). A Atividade é um recurso que a TO se apropria para poder promover ao paciente um novo significado ao seu fazer (S5). Ela pode ser um meio para alcançar algo e pode até ser mesmo o próprio fim/objetivo da intervenção. Pode ser a própria intervenção terapêutica, ainda mais em sujeitos que desaprenderam ofazer ou não se orientam mais para este (S8, grifo nosso).

Outras respostas basearam-se na perspectiva da atividade com função curativa, visando a reabilitação do sujeito.

A Atividade é usada para reabilitar o paciente nas áreas física, mental e social e desenvolver novas habilidades para uma melhor adaptação no meio no qual o mesmo vive e desenvolve suas funçōes (S9). A Atividade é um recurso do cotidiano de qualquer ser humano, não é especifico da TO. A TO sabiamente se utiliza dela, que é inerente à qualquer um, como um recurso para restabelecer a saúde (mental, emocional, física, social etc.) (S10).

\subsubsection{Objetivos da terapia ocupacional nos CAPS ad}

As terapeutas ocupacionais, quando indagadas sobre os objetivos de seu trabalho nos CAPS ad, apresentaram um repertório amplo de opçóes, das quais destacamos aquelas relacionadas à criação de estratégias de (re)tomada de atividades em seu cotidiano:

Reestabelecer trabalho, autonomial independência; Resgatar laços familiares; Estratégias de inserção social; Desenvolver potencial funcional; Recuperar aptidóes; Reconstituir cotidiano (S5). Retomar projetos de vida, promover recuperação de vinculos, desenvolver habilidades que possam ser utilizadas para futura geração de renda (S7). (Re)inserção no mercado de trabalhol escola, organização de rotinas (S11 e S12).
Orientação/preparação dos familiares, sensibilização e orientação à comunidade (S11).

Em relação aos objetivos específicos relacionados à dependência química, as terapeutas ocupacionais afirmam:

Proporcionar melhor qualidade de vida durante os processos de abstinência (S1). Auxiliar na reestruturação do cotidiano dos pacientes. Buscar novos interesses, novas habilidades, bem como a reflexão do papel da dependência em sua trajetória (S3). Objetivo primário: levantar quais os motivos que desencadeiam o uso da substância; Objetivo secundário: apontar para o paciente o fator desencadeante e ajudá-lo a enfrentar sua realidade sem o uso da substância (S6). Proporcionar vivências de novas experiências e maneiras de lidar com situaçóes que levaram ao uso da droga (S7). Acolher, orientar, informar, aconselhar em dependência química, motivar para o tratamento, prevenir recaidas (S12). Procurar facilitar um processo de motivação e autoconhecimento do usuário que possa permitir a redução ou cessação de substâncias psicoativas (S13).

Além desses, os relatos mostraram que os objetivos da profissão também estão voltados para aspectos psicológicos e afetivos dos sujeitos, tais como, "ampliação de recursos mentais, emocionais e práticos" (S2); "criar estratégias de confronto do sentimento com as emoçôes que vão ter repercussóes no dia a dia"(S5); "capacitação para enfrentamento de frustraçōes [...] recuperação ou otimizaçấo da autoestima, capacitação para enfrentamento de frustraçôes" (S11).

Pelos trechos acima elencados, observa-se que não há um consenso entre as profissionais sobre os objetivos de sua intervenção tampouco uma nomenclatura comum para a descrição do trabalho realizado. Dessa forma, aponta-se a necessidade de aprofundamento nesse aspecto, com o intuito de melhor desvelar sobre a pluralidade que vem sendo desenvolvida pelos terapeutas ocupacionais, como o objetivo de efetivaçáo de inserção social via ações terapêutico-ocupacionais vem se tecendo naqueles serviços, assim como o impacto significativo para seus usuários.

\subsubsection{Equipamentos e materiais ofertados pela instituição/serviço}

Em 50\% das respostas sobre materiais ofertados e utilizados nas instituiçôes ${ }^{8}$, foi afirmada a necessidade de improvisação, como disse a colaboradora: "É preciso improvisar, pois não há material suficiente”. 
Quarenta e três por cento das terapeutas ocupacionais consideraram que os equipamentos e materiais são escassos, sendo essa a mesma porcentagem daquelas que os consideraram suficientes.

Trinta e seis por cento das profissionais afirmam adquirir materiais com recursos próprios e $29 \%$ buscam doaçôes.

\subsubsection{Importância da terapia ocupacional}

Foi questionado às profissionais qual era sua opinião sobre a importância da terapia ocupacional para o público-alvo em questão. As respostas a esse item foram similares aos objetivos relatados pelas profissionais, tais como "promover a qualidade de vida”, desenvolver/restaurar habilidades, capacidades, autonomia e independência dos sujeitos, bem como favorecer o processo de reinserção social e familiar dessas pessoas.

A busca por novos interesses foi citada como um fator a ser intermediado pelo terapeuta ocupacional na relação terapeuta-paciente que estabelece com os usuários, bem como reconstruir cotidianos através dessas relaçôes.

A importância dessa categoria profissional fica evidente nos relatos coletados: "A Terapia Ocupacional olha para o cotidiano adoecido pelo consumo de álcool e outras drogas e propóe novas formas de relação com os limites pessoais e com as substâncias usadas". $\mathrm{Ou}$, ainda: "A Terapia Ocupacional proporciona a concretização de fazeres e projetos de vida, que se encontram rompidos nos dependentes quimicos".

Uma terapeuta ocupacional destaca:

\section{A Terapia Ocupacional é essencial. Os meios que ela utiliza são próprios da nossa atuação e atingem esse público com facilidade. A linguagem da Terapia Ocupacional, principalmente com adolescentes, tem muita efetividade. Além dos meios, o nosso olhar para a funcionalidade é necessário no tratamento da Dependência Quimica.}

E, por fim, afirma uma terapeuta ocupacional que a profissáo compóe uma equipe de trabalho, devendo trazer nesse espaço sua percepção de atividade e cotidiano humanos, bem como sua integração com a realidade onde vive, "Cuidar para que o CAPS possa ser um espaço terapêeutico e não de exclusão".

Dessa forma observa-se, uma vez mais, a pouca apropriação da identidade profissional nesse campo e a multiplicidade de respostas que dialogam para um objetivo comum, porém não se apresentam de forma sistematizada nesse fim.

\subsubsection{Concepções acerca dos recursos / atividades}

Observou-se, no universo analisado, uma presença importante das terapeutas ocupacionais na composição das equipes dos CAPS ad, com um perfil de uma maioria (56\%) formada há menos de cinco anos, estando $93 \%$ em processo de continuaçáo de sua formação.

Contudo, apenas $38 \%$ se voltaram para a área de saúde mental com ênfase em drogas, demonstrando a necessidade de discussôes mais aprofundadas acerca das possibilidades da categoria para a realização de formaçáo continuada, a oferta disponível, seus custos e possibilidades concretas de educaçáo permanente direcionada à melhora dos serviços públicos ofertados.

Um ponto de relevância para a equipe em geral e, em particular, para o terapeuta ocupacional, refere-se à diretriz nacional da Redução de Danos. Surpreendeu que apenas $21 \%$ relataram que fundamentavam suas intervençôes em tal perspectiva, claramente apresentada nos documentos como referência para o trabalho. Entretanto, isso reflete uma cultura moral em que a proposição ideológica da Redução de Danos não é aceita socialmente, sendo mantidas lógicas que incrementam a proposição da abstinência como única forma de tratamento e missão de tais serviços. Catorze por cento citaram essa estratégia como único recurso utilizado, possibilitando o atual debate em torno de estratégias de internaçáo e atendimento privado para as pessoas que necessitem de algum tipo de atenção frente ao uso de drogas. Embora esse quadro náo tenha sido observado em $100 \%$ das entrevistadas e, ainda, $21 \%$ tenham declarado explicitamente sobre a Redução de Danos, é preciso que o tema seja colocado em debate.

Voltando-se especificamente para os recursos de que o terapeuta ocupacional lança mão, ressalta-se a estratégia grupal. Ballarin (2011, p. 41) aponta a complexidade de tal trabalho, destacando: "[...] muitos dos fenômenos vivenciados nesse contexto possibilitam a emergência de processos de identificação, a troca de experiência e o contínuo estímulo ao processo ensino-aprendizagem". A autora assinala que os grupos de terapia ocupacional podem assumir formatos diversos de acordo com as diferentes instituições e contextos.

As colaboradoras citaram, também, temas que necessitam de maior atenção, que emergem de sua prática, tais como: a falta de adesão dos usuários ao serviço; a internação compulsória, apontada como elemento que dificulta o tratamento; a falta de articulação com a rede de assistência e a ausência de aplicação dos princípios da Reforma Psiquiátrica no 
cotidiano dos serviços no campo da Saúde Mental. Referem-se a elementos de extrema relevância e complexidade que carecem de maior compreensão teórica, a ser alcançada na reflexão conjunta com os profissionais da prática, na direção do desenvolvimento de açôes mais libertárias, em um contexto aberto e que, acima de tudo, respeite a pessoa que faz uso de drogas como cidadão.

Assim, espera-se que o conhecimento e a prática em terapia ocupacional, em consonância e composição com as demais áreas, possam contribuir para a complexa demanda social em torno da droga, sua valoração e alternativas de cuidado e atenção.

\section{Considerações finais}

Por meio do mapeamento elaborado, pudemos observar que os CAPS ad do interior do estado de Sáo Paulo relataram aspectos presentes na diretriz nacional acerca do funcionamento do serviço, como possuir equipe mínima, atuar de forma articulada com outros dispositivos disponíveis no município e caracterizar-se como "portas abertas" no sistema.

Porém, falas sobre o despreparo da equipe, a falta de capacitaçáo dos profissionais na área e o fato de nenhum desses CAPS ad possuir leitos apontam elementos necessários de atuação e intervenção pelo âmbito público.

Outro fator é que, apesar de alguns colaboradores terem respondido sobre a articulação com os demais dispositivos da rede de atendimento, foi possível notar uma concentração nos serviços de saúde, mostrando uma circunscrição do problema que não dialoga com sua complexidade e, portanto, com as demais áreas das políticas sociais.

Mesmo no interior do setor Saúde, apesar de a Redução de Danos ser a proposta nacional de intervenção no CAPS ad, ela foi pouco citada entre as políticas que têm impactado o cotidiano dos serviços, o que nos leva a pensar sobre a maneira que ela realmente tem sido empregada, quanto os profissionais compreendem tal política e, ainda, se a sociedade compreende e concorda com essa estratégia de ação para com aqueles que fazem uso de drogas.

Em especial, o trabalho do terapeuta ocupacional aparece de forma a extrapolar as questôes de saúde o que necessariamente levaria às dimensóes intersetoriais, sobretudo quando as questôes relacionadas ao trabalho, geração de renda, estudo e escolarizaçáo aparecem como importante ação desse profissional. Além disso, os objetivos terapêuticos ocupacionais estão pautados em dimensões humanas impossíveis de serem segmentadas, visando redimensionamento dos projetos de vida, promoção e produção de vida. O que revela também desafios de ordem macrossocial que devem ser considerados.

Destaca-se o fato de nenhum profissional ter mencionado a questáo do tráfico de drogas como elemento influente nesse contexto. Embora o questionário não perguntasse diretamente sobre esse ponto, esperava-se uma resposta espontânea sobre tal tema, visto sua complexidade e indissociabilidade com a realidade dos usuários daqueles serviços. Fica a dúvida de como os profissionais envolvidos nesse serviço lidam com esse tema, em seu dia a dia, ou se alijam a discussão do uso de drogas, de sua distribuição e acesso, principalmente relacionada a jovens e moradores de periferias, declarada como a maior concentração de usuários dos CAPS ad.

Por fim, assinala-se a necessidade de mais estudos sobre os CAPS ad, seus profissionais, usuários e sua eficácia, visto que esse é um serviço que tem sido compreendido como estratégico na ação social frente ao "problema" das drogas, tema que perpassa diferentes esferas, áreas e imaginários. Ainda, faz-se necessário também um aprofundamento no campo da Terapia Ocupacional para que se busque apreender quais conhecimentos têm sido constituídos, assim como qual a contribuição do profissional com esse complexo universo de demandas na contemporaneidade.

Esperamos que os serviços voltados à população que faz uso de drogas possam, de forma efetiva, colaborar com a sua vida, sem julgamentos morais, estigmatizações ou simplificação de importante temática da sociedade contemporânea.

\section{Referências}

BALLARIN, M. L. G. S. Abordagens grupais. In: CAVALCANTI, A.; GALVÃO, C. Terapia Ocupacional: fundamentação e prática. Rio de Janeiro: Guanabara Koogan, 2011. p. 38-43.

BERRIDGE, V. Dependência: história dos conceitos e teorias. In: EDWARDS, G.; LADER, M. (Org.). A natureza da dependência de drogas. Porto Alegre: Artes Médicas, 1994. p. 13-34.

BRASIL. Lei no 10.216, de 6 de abril de 2001. Dispóe sobre a proteção e os direitos das pessoas portadoras de transtornos mentais e redireciona o modelo assistencial em saúde mental. Diário Oficial da União, Poder Executivo, Brasília, DF, 9 abr. 2001. Disponível em: <http:// www.planalto.gov.br/ccivil_03/leis/leis_2001/110216. htm>. Acesso em: 28 jun. 2014.

BRASIL. Ministério da Saúde. Secretaria de Atenção à Saúde. A política do Ministério da Saúde para atenção integral a usuários de álcool e outras drogas. Brasília, 2004 a. 
BRASIL. Ministério da Saúde. Secretaria de Atenção à Saúde. Álcool e redução de danos: uma abordagem inovadora para países em transição. Brasília, 2004b.

BRASIL. Ministério da Saúde. Secretaria de Atenção à Saúde. Departamento de Açóes Programáticas Estratégicas. Saúde mental no SUS: os centros de atenção psicossocial. Brasília, 2004c.

BRASIL. Lei no 11.343, de 23 de agosto de 2006. Institui o Sistema Nacional de Políticas Públicas sobre Drogas - Sisnad. Prescreve medidas para prevenção ao uso indevido, atenção e reinserção social de usuários e dependentes de drogas; estabelece normas para repressão à produção não autorizada e ao tráfico ilícito de drogas; define crimes e dá outras providências. Diário Oficial da União, Poder Executivo, Brasília, DF, 24 ago. 2006. Disponível em: <http://www.planalto.gov.br/ccivil_03/_ato2004-2006/2006/lei/111343.htm>. Acesso em: 9 dez 2013.

BRASIL. Ministério da Saúde. Secretaria de Atenção à Saúde. Departamento de Açóes Programáticas Estratégicas. Relatório de Gestão 2003-2006. Saúde mental no SUS: acesso ao tratamento e mudança do modelo de atenção. Brasília, 2007.

BRASIL. Ministério da Saúde. Conselho Nacional de Saúde. Sistema Único de Saúde - SUS. Comissão Organizadora da IV Conferência Nacional de Saúde Mental Intersetorial. Relatório Final da IV Conferência Nacional de Saude Mental - Intersetorial, 27 de junho a 1 de julho de 2010. Brasília, 2010.

BRASIL. Ministério da Justiça. Secretaria Nacional de Políticas sobre Drogas - SENAD. Prevenção ao uso indevido de drogas: capacitação para Conselheiros e Lideranças Comunitárias. Brasília, 2011a.

BRASIL. Ministério da Saúde. Portaria no 3.088, de 23 de dezembro de 2011. Institui a Rede de Atençâo Psicossocial para pessoas com sofrimento ou transtorno mental e com necessidades decorrentes do uso de crack, álcool e outras drogas, no âmbito do Sistema Único de Saúde (SUS). Diário Oficial da Uniāo, Poder Executivo, Brasília, DF, 2011b. Disponível em: <http://bvsms.saude.gov. br/bvs/saudelegis/gm/2011/prt3088_23_12_2011_rep. html>. Acesso em: 28 jun. 2014.

BRASIL. Centro Cultural do Ministério da Saúde. Caps e outros serviços. Brasília. Disponível em: <http://www. ccs.saude.gov.br/saudemental/capssaopaulo.php $>$. Acesso em: 10 fev. 2012.

BRASIL. Ministério da Justiça. Política sobre Drogas. Caucaia, Juazeiro do Norte e Maracanaú aderem ao Programa Crack. Brasília, 2013. Disponível em: <http:// portal.mj.gov.br/main.asp?ViewID=\%7BB65AD46B7869-40ED-B5EC-1652B28565BC\%7D\&params $=\mathrm{i}$ temID $=\% 7 \mathrm{~B} 9550411 \mathrm{D}-1 \mathrm{C} 40-4193-\mathrm{B} 0 \mathrm{~F} 1-\mathrm{DB} 58 \mathrm{DF}$ CC2696\%7D; \&UIPartUID=\%7B2218FAF9-5230431C-A9E3-E780D3E67DFE\%7D>. Acesso em: 9 dez. 2013.
BUCHER, R.; OLIVEIRA, S. R. M. O discurso do "combate às drogas" e suas ideologias. Revista de Saúde Pública, São Paulo, v. 28, n. 2, p. 137-145, 1994. http:// dx.doi.org/10.1590/S0034-89101994000200008. PMid:7824847.

CASTRO, E. D.; LIMA, E. M. F. A.; BRUNELLO, M. I. B. Atividades humanas e Terapia Ocupacional. In: DE CARLO, M. M. R. P.; BARTALOTTI, C. C. Terapia Ocupacional no Brasil: fundamentos e perspectivas. São Paulo: Plexus, 2001. p. 41-59.

CONSELHO FEDERAL DE PSICOLOGIA - CFP. Nem comunidades, nem terapêuticas. Brasília. Disponível em: <http://site.cfp.org.br/nem-comunidades-nem-terapeuticas/>. Acesso em: 16 maio 2013.

DELGADO, P. G. Drogas: o desafio da saúde pública. In: ACSELRAD, G. (Org.). Avessos do prazer: drogas, AIDS e direitos humanos. Rio de Janeiro: Fiocruz, 2005. p. 165-181.

GALHEIGO, S. Terapia Ocupacional: a produção do conhecimento e o cotidiano da prática sob o poder disciplinar: em busca de um depoimento coletivo. 1988. 84 f. Dissertação (Mestrado em Educação)-Universidade Estadual de Campinas, Campinas, 1988.

GALLASSI, A. D.; SANTOS, V. O abuso de drogas: desafios e opçóes para a prática do profissional de saúde no Brasil. Revista Brasília Médica, Brasília, v. 50, n. 1, p. 51-57, 2013.

HUXLEY, A. As portas da percepção: céu e inferno. São Paulo: Globo, 2002.

INTERNATIONAL HARM REDUCTION ASSOCIATION - IHRA. O que é redução de danos? Uma posição oficial da Associação Internacional de Redução de Danos (IHRA). London. Disponível em: <http://www. ihra.net/files/2010/06/01/Briefing_what_is_HR_Portuguese.pdf>. Acesso em: 9 dez. 2013.

KARAGUILLA, M. A experiência criativa no tratamento de dependentes de substâncias psicoativas: a intervenção da Terapia Ocupacional. 2010. 183 f. Dissertação (Mestrado em Ciências)-Universidade Federal de São Paulo, São Paulo, 2010.

LIMA, E. M. F. A.; OKUMA, D. G.; PASTORE, M. N. Atividade, ação, fazer e ocupação: a discussão dos termos na terapia ocupacional brasileira. Cadernos de Terapia Ocupacional da UFSCar, São Carlos, v. 21, n. 2, p. $243-$ 254, 2013. http://dx.doi.org/10.4322/cto.2013.026.

MEDEIROS, M. H. R. Terapia Ocupacional: um enfoque epistemológico e social. $1^{\text {a }}$ reimp. São Carlos: EdUFSCar, 2010.

OLIVEIRA, Y. A clínica terapêtica ocupacional com usuários de substâncias psicoativas: o desafio da práxis. Revista Brasileira em Promoção da Saúde, Fortaleza, v. 19, n. 4, p. 229-233, 2006. http://dx.doi. org/10.5020/18061230.2006.p229. 
PEREIRA, P. E.; MALFITANO, A. P. S. Percursos Metodológicos para a Apreensão de Universos de Adolescentes e Jovens: um enfoque sobre a questão das drogas. Revista Brasileira de Crescimento e Desenvolvimento Humano, São Paulo, v. 22, n. 3, p. 334-340, 2012.

RODRIGUES, T. Política de drogas e a lógica dos danos. Revista Verve, São Paulo, n. 3, p. 257-277, 2003. Disponível em: <http://revistas.pucsp.br/index.php/ verve/article/viewFile/4947/3495>. Acesso em: 25 nov. 2012 .

SÃO PAULO (Estado). Secretaria de Saúde. Secretaria de Desenvolvimento Social. Secretaria de Justiça. Programa Recomeço: Programa Estadual de enfrentamento ao crack. São Paulo. Disponível em: <http://www.saude. sp.gov.br/resources/ces/homepage/destaques/pleno-227/ programa_recomeco_para_publicacao.pdf $>$. Acesso em: 3 out. 2014.

TEDESCO, S. Terapia Ocupacional: produzindo uma clínica de atenção às dependências. Revista do CETO, São Paulo, v. 2, n. 2, p. 16-19, 1997.

UNITED NATIONS OFFICE ON DRUGS AND CRIME - UNODC. World Drug Report 2013. Vienna, 2013. (United Nations Publication, Sales n. E.13.XI.6). Disponível em: <http://www.unodc.org/unodc/secured/ wdr/wdr2013/World_Drug_Report_2013.pdf >. Acesso em: 9 dez. 2013.

UNITED NATIONS OFFICE ON DRUGS AND CRIME - UNODC. World Drug Report 2014. Vienna, 2014. Disponível em: <http://www.unodc.org/ wdr2014/>. Acesso em: 2 out. 2014.

\section{Contribuição dos Autores}

Carla Regina Silva e Ana Paula Serrata Malfitano foram responsáveis pela orientação dos trabalhos e pelas análises realizadas. Caroline Santos e Juliana Nogueira realizaram a coleta e a análise dos dados. Todas as autoras aprovaram a versão final do texto.

\section{Notas}

${ }^{1}$ Este artigo é fruto dos Trabalhos de Conclusão de Curso em Terapia Ocupacional pela Universidade Federal de São Carlos (UFSCar) das graduandas Caroline Santos e Juliana Nogueira. Todos os procedimentos éticos foram respeitados.

${ }^{2}$ Segundo o Relatório Mundial sobre Drogas (UNITED..., 2013), o uso de cocaína tem aumentado significativamente no Brasil, sendo que se estima o uso por $1,75 \%$ da população geral. O uso de cannabis na América do Sul é o mais elevado (5,7\%) das Américas, enquanto o uso de opioides (0,3\%) e Ecstasy $(0,1 \%)$ continuam bem abaixo da média global. O relatório apresenta também o aumento do uso de novas substâncias psicoativas que incluem a ketamina e substâncias à base de plantas, seguidas de piperazinas, catinonas sintéticas, feniletilaminas e, em menor extensão, os canabinóides sintéticos.

3 O termo "combate" utilizado no texto refere-se à expressão vastamente empregada em diferentes setores sociais, tais como políticas e mídias, ao se referirem à ação contra ao uso de substâncias lícitas e ilícitas no país. Corrobora-se com Bucher e Oliveira (1994, p. 137) quando afirmam que essa ideologia é disciplinadora, condenatória, alarmista e repressiva, pois “[...] a cegueira da posição repressiva radical traz mais estragos que benefícios por fazer prevalecer uma visão unidimensional, inapropriada para o trato do fenômeno em toda sua complexidade".

${ }^{4}$ A Associação Internacional de Redução de Danos (AIRD) define a Redução de Danos como um conjunto de políticas e práticas cujo objetivo é reduzir os danos associados ao uso de drogas psicoativas em pessoas que não podem ou não querem parar de usar drogas. Por definição, redução de danos foca na prevenção aos danos, ao invés da prevenção ao uso de drogas; bem como foca em pessoas que seguem usando drogas (INTERNATIONAL..., 2013).

${ }^{5}$ Programa lançado pelo governo federal em 2012, com a finalidade de prevenir o uso e promover a atenção integral ao usuário de crack, bem como enfrentar o tráfico de drogas. Tem por objetivo aumentar a oferta de serviços de tratamento e atenção aos usuários e seus familiares, reduzir a oferta de drogas ilícitas por meio do enfrentamento ao tráfico e às organizaçôes criminosas e promover açôes de educaçáo, informação e capacitação. Até junho de 2013, haviam 66 cidades brasileiras que aderiram ao programa (BRASIL, 2013).

${ }^{6}$ O levantamento dos dados foi realizado no primeiro semestre de 2012.

${ }^{7}$ Uma terapeuta ocupacional não respondeu a esse item do questionário, portanto, foram consideradas 13 respostas.

${ }^{8}$ A seguir, as opçóes elencadas no questionário, em relação aos equipamentos e materiais ofertados pela instituição/serviço para a prática terapêutica ocupacional: a. possui muita quantidade; b. são suficientes, c. são escassos, d. é preciso improvisar, pois não há material suficiente, e. costumo conseguir doaçōes, f. trago materiais de casa, g. há muita diversidade de materiais, h. a diversidade de materiais é suficiente e i. há pouca diversidade de materiais. 